\begin{tabular}{|c|l|}
\hline Title & $\begin{array}{l}\text { Punishments and dispute settlement in trade agreements : the equivalent } \\
\text { withdrawal of concessions }\end{array}$ \\
\hline Sub Title & \\
\hline Author & Ethier, Wilfred J. \\
\hline Publisher & Keio Economic Society, Keio University \\
\hline Publication year & 2005 \\
\hline Jtitle & Keio economic studies Vol.42, No.1/2 (2005. ),p.1- 23 \\
\hline JaLC DOI & \\
\hline Abstract & $\begin{array}{l}\text { I interpret dispute settlement procedures and the principle of equivalent } \\
\text { withdrawal ofconcessions as responses to the fact that trade agreements are } \\
\text { incomplete contracts. With no adjudication phase and the degree of trade } \\
\text { relatedness known with certainty, an agreement will feature commensurate } \\
\text { punishments, will induce violation of the dispute settlement ruling, and will } \\
\text { deliver optimal liberalization and optimal unilateral trade-related action. With an } \\
\text { adjudication phase, the agreement will feature less liberalization, but still } \\
\text { presumably approximate commensurate punishment. The agreement will likely } \\
\text { induce abiding by the ruling when negotiators attach more importance } \\
\text { to the adjudication phase, and violating it when they attach less. }\end{array}$ \\
\hline Notes & Special issue in honor of Prpfessor Michihiro Ohyama \\
\hline Genre & ournal Article \\
\hline URL & $\begin{array}{l}\text { https://koara.lib.keio.ac.jp/xoonips/modules/xoonips/detail.php?koara_id=AA002 } \\
\text { 60492-20050001-0001 }\end{array}$ \\
\hline
\end{tabular}

慶應義塾大学学術情報リポジトリ(KOARA)に掲載されているコンテンツの著作権は、それぞれの著作者、学会または出版社/発行者に帰属し、その 権利は著作権法によって保護されています。引用にあたっては、著作権法を遵守してご利用ください。

The copyrights of content available on the KeiO Associated Repository of Academic resources (KOARA) belong to the respective authors, academic societies, or publishers/issuers, and these rights are protected by the Japanese Copyright Act. When quoting the content, please follow the Japanese copyright act. 


\title{
PUNISHMENTS AND DISPUTE SETTLEMENT IN TRADE AGREEMENTS: The Equivalent Withdrawal of Concessions
}

\author{
Wilfred J. ETHIER \\ Department of Economics, University of Pennsylvania, Philadelphia, USA \\ First version received October 2005; final version accepted November 2005
}

\begin{abstract}
I interpret dispute settlement procedures and the principle of equivalent withdrawal of concessions as responses to the fact that trade agreements are incomplete contracts. With no adjudication phase and the degree of trade relatedness known with certainty, an agreement will feature commensurate punishments, will induce violation of the dispute settlement ruling, and will deliver optimal liberalization and optimal unilateral trade-related action. With an adjudication phase, the agreement will feature less liberalization, but still presumably approximate commensurate punishment. The agreement will likely induce abiding by the ruling when negotiators attach more importance to the adjudication phase, and violating it when they attach less.
\end{abstract}

Key words: Incomplete Contracts, Reciprocal Conflict, Substantially Equivalent Withdrawal Of Concessions, Commensurate Punishment, Abidement Property.

JEL Classification Codes: F02, F13.

OVER THIRTY YEARS AGO, Michihiro Ohyama, my Rochester classmate, published in this journal a classic contribution [Ohyama (1972)] to the normative theory of international trade. More recently, he has been investigating issues relevant to the World Trade Organization (WTO). Indeed, negotiated trade liberalization under the auspices of the General Agreement on Tariffs and Trade (GATT) and the WTO has been the big international economic story of the last sixty years. The GATT contained a dispute settlement procedure (DSP) which proved to be of only spasmodic significance. The Uruguay Round of multilateral trade negotiations, which established the WTO, significantly changed this procedure in the hopes of increasing its use. These hopes, at least, have not been frustrated.

\footnotetext{
Acknowledgements. I thank Catherine Yuhe Chang, Arye Hillman, Henrik Horn, and Peter Rosendorff for many useful exchanges, seminar participants at Columbia, Kiel, Munich, New Orleans, and Southern Methodist Universities for helpful comments, and EPRU in Copenhagen for a congenial environment in which to pursue this research.

E-mail: ethier@econ.sas.upenn.edu

Copyright(C)2005, by the Keio Econimic Society
} 
But the recent vociferous (and sometimes violent) protests of environmentalists and social activists have been motivated to a significant (and perhaps dominant) degree by the decisions of the WTO DSP. This paper addresses, in such a context, the economic role of a system of punishments and dispute settlement.

\section{INTRODUCTION}

The GATT/WTO trade liberalization has had to deal with numerous trade disputes between individual countries, and the need to address these has produced a multilateral response.

These disputes within the GATT DSP, outside of it, or within the WTO DSP and the response, can be summarized by the following stylized facts.

1. Trade disputes are inherently bilateral, not multilateral.

The direct participants to trade disputes (whether two or several), and only they, initiate the disputes, force their timing, undertake negotiations to settle, and inflict punishments. This is true even if the dispute is conducted within a multilaterally-established DSP. ${ }^{1}$ Indeed, a major function of such a system is to keep disputes bilateral by inducing aggrieved nations to go before a panel of experts rather than to seek allies among third countries. This is not necessarily a good thing: An insightful contribution by Maggi (1999) has shown that, in the presence of strategic complementarities across governments imposing tariffs on the same good, a multilateral DSP could enlarge aggregate punishment beyond that obtainable as a sum of bilateral punishments, allowing the negotiation of more multilateral liberalization.

2. A formal DSP was created and continues to evolve.

The procedure was created years ago by the GATT, but the most important steps in its evolution were the Uruguay Round changes mentioned above, embodied in the Dispute Settlement Undertaking of that agreement.

3. The DSP of the WTO has almost always decided in favor of the complainant $(C)$ and, therefore, against the defendant $(D)$.

Defendants clearly won only 2 of the first 44 decisions under the WTO system. Countries file complaints only when confident (usually rightly) that their complaints are justified, and not to acquire a "tough" reputation or to extract a nuisance value. This, too, has basically been the case when a DSP has not been utilized: Countries have provoked confrontations only when confident that concessions would result.

4. Punishments for alleged violations of past agreements have been delayed.

A decision to utilize a DSP is in practice a decision to delay punishment until that procedure has run its course. But, even when a DSP is not utilized, countries convinced that partners have violated trade agreements have consistently chosen to negotiate first, and to threaten punishments should the negotiations fail, rather than immediately to punish, and then to cease the punishments should the negotiations succeed.

\footnotetext{
I Third countries with a vital interest in a matter under dispute between major countries sometimes sign on as participants (the banana war between the US and the EU being a notable example). This can be the easiest way for small countries to participate in the system.
} 
5. Defendants have (much more often than not, at least since the institution of the WTO procedure) abided by the decisions of the DSP. But a number of important, highly visible, cases, involving major countries, have resulted in prolonged violations of DSP decisions.

The decisions to abide have been widely viewed as evidence of the "success" of the WTO DSP (unwelcome success, in the opinion of many environmentalists and social activists), whereas the violations (notably the US-EU disputes on hormone-fed beef and bananas) have been viewed as "failures" that threaten the viability of a "rules-based" system.

6. Punishments for alleged violations of past agreements have consistently been commensurate with the violations (i.e., tit-for-tat).

This has been true regardless of whether the punishments, or threatened punishments, have been unilateral or products of a DSP. Indeed, this can be regarded as just one facet of the principle of substantially equivalent withdrawal of concessions, pervasive throughout the GATT: See Articles XIX, XXIII, and XIV of the GATT. If a country "fails" an obligation to provide some trade liberalization, its trading partners can also withdraw from their obligations to liberalize to a substantially equivalent degree.

These are very special properties. What is the role of such a system? This paper develops a model to propose answers to these questions and to investigate both the general principle of substantially equivalent withdrawal of concessions and also the role of a DSP. Specifically, I shall depend on stylized facts 1-3 (especially $\mathbf{1}$ and $\mathbf{3}$ ) to motivate my model, which I then use to analyze 5 and $\mathbf{6}$.

\subsection{Incomplete contracts}

Trade agreements are necessarily incomplete contracts; the DSP, weak punishments, and the principle of substantially equivalent withdrawal of concessions deal with that situation in a context in which individual countries sometimes will be tempted to implement a trade related policy and sometimes will have their trade influenced by a partner's implementation of such a policy.

Incomplete-contract problems arise because the subsequent state of the world is not known when negotiations take place. Any agreement must reflect this. The most straightforward way to deal with it is to negotiate state-contingent agreements. But these have severe limitations: The negotiation of even state-invariant changes in recognized policy instruments has become enormously complicated and time consuming. So, negotiated trade agreements necessarily remain, by their very nature, incomplete contracts. This is implicitly acknowledged in the GATT itself, where Articles XXII and XXIII allow response to a "nullification or impairment" of concessions not necessarily the result of an explicit repudiation of a trade agreement.

Trade agreements address a limited number of policy instruments that pertain directly to trade, but governments care about economic outcomes, not about the instruments that can be negotiated. And trade is one aspect of the general equilibrium that depends upon all economic instruments. So, ex post, governments will be doing things that influence 
trade and that have not been explicitly addressed by trade agreements: a recipe for disagreement about the constraints implied by those agreements.

Each country is aware, ex ante, that it may find itself, ex post, harmed by a policy that some trading partner wishes to make. So the former will want a recognized punishment procedure as a deterrent. But that country will also be aware, ex ante, that it might find, ex post, itself in a position where it would be costly not to take some policy action that would harm a partner. This is the reciprocal-conflict problem: Each country knows that it might turn out to be either the accuser or the accused. Thus it is in no country's interest, ex ante, to agree that, ex post, either the accuser should be unconstrained in its ability to punish or the accused should be unconstrained in its ability to proceed without punishment. This generates a role for a dispute settlement mechanism.

The above argument can motivate the use of either an explicit dispute-settlement mechanism (as under the WTO) or an implicit agreement by countries not to punish without first attempting to negotiate a solution and also spelling out in advance what punishments will be used (as with the U.S. Section 301, and as when trade disputes under the GATT were not submitted to GATT procedures). Furthermore, the theory that follows can also be interpreted as an explanation of the practice of "withdrawal of equivalent concessions," basic to the GATT from its very beginning. In what follows there is no need to distinguish among these alternatives; for concreteness I simply consider a formal dispute settlement mechanism.

Much of the theoretical literature on DSPs ${ }^{2}$ assumes that trade policies of partners are imperfectly observable and that the procedures serve to transmit information between agents. But actual trade disputes generally proceed from the observation and address what to do about these clearly observed policies. ${ }^{3}$ Nor does a central purpose of such procedures seem to be to resolve basic uncertainty about whether specific policies are or are not in fact consistent with trade agreements. As pointed out above, WTO DSP decisions normally go against the defendant. Indeed, in the more visible cases, the financial press routinely and correctly predicts in advance which way decisions will go. So, to focus sharply on the fact that trade agreements are incomplete contracts, I shall oversimplify a bit and assume away both informational asymmetries and uncertainty about whether a policy under dispute does in fact violate trade agreements. The purpose of a DSP instead will be (i) to supply a formal international statement that such a policy is in fact a violation, (ii) to specify explicitly how it is in violation, and (iii) to provide, if necessary, a neutral assessment of the "damage" caused by that policy.

\footnotetext{
2 This literature includes Hungerford (1991), Ludema (2001), Kovenock and Thursby (1992), Maggi (1999), Furusawa (1999), Bütler and Hauser (2000), and Rosendorff (2000). Staiger (1995) contains an insightful survey. Related issues arise in Bagwell and Staiger (2001).

3 Recall the most prominent trade disputes over the last 40 years: the "chicken war" between the US and the EC, the US-EC dispute over EC policy toward oilseed production, US-EU disputes about U.S. hormonefed beef and genetically modified foods, the "banana war" between the US and the EU, complaints about US policies toward Venezuelan oil and toward tuna caught in "dolphin-unfriendly" ways. In all these cases the policies of the accused were common knowledge: It was their acceptability that was under dispute.
} 
Thus I focus on disputes about policy actions that, though not explicitly mentioned in trade agreements, are nonetheless widely perceived to be in violation of those agreements. These correspond to what are called violation complaints to the WTO DSP. The relevance of my approach to non-violation complaints is less clear. But this is of little consequence: Nonviolation complaints are not of large practical significance.

\subsection{Why countries delay punishment}

The use of such a mechanism cannot be costless. It implies that punishments must be delayed, because the implementation of a controversial policy by some country cannot be required to wait until the dispute settlement mechanism renders its verdict. The reason the mechanism exists in the first place is that no one knows in advance what will come into dispute: Trade agreements are incomplete contracts. So the only way to delay implementation is to require that this be automatically required for any policy action that is disputed, and this would in effect give each country a temporary veto over every economic policy action of every other country, hardly acceptable to anyone.

This is my explanation for why countries choose to delay punishment when they don't have to: THEY ATTACH IMPORTANCE TO THE FACT THAT TRADE AGREEMENTS ARE INCOMPLETE CONTRACTS.

The paper proceeds as follows. Sections 2 and 3 set out the basic model. Section 4 discusses a special case which can be interpreted as an explanation of the principle of the substantially equivalent withdrawal of concessions, and Sections 5 and 6 then discuss the negotiation of a trade agreement featuring a DSP in more general circumstances. The analysis implies a strong presumption that countries will choose to employ titfor-tat punishments (or the substantially equivalent withdrawal of concessions), and provides an analysis of the circumstances under which countries are likely to negotiate trade agreements that will induce violations of DSP rulings.

\section{AN ABSTRACT FRAMEWORK}

I first provide a simple framework for the analysis that follows.

\subsection{The background}

Assume two goods, $A$ and $B$, and two factors of production. In light of the stylized fact that trade disputes are not inherently multilateral, I also assume 2 countries. One has a comparative advantage in $A$ and the other in $B$; otherwise they are identical. Technology is neoclassical. Assume a succession of periods. Both factors are mobile between sectors across periods, but immobile within each period. All consumers spend equally on both goods.

Initially, each country has an historically given tariff $t$ on all imports. This comes from a highly protectionist past: I shall not investigate why the present is less protectionist. For simplicity I suppose that this initial tariff is common to both countries. Also, factors in each country are initially allocated between the two sectors. Governments negotiate changes in initial tariffs; I shall not model the negotiations. The inter-sectoral immobility of factors during the period ensures that one interest group prefers more 
protection and one prefers less. When the governments negotiate changes in their tariffs they do not know the exact state of the world that will pertain when those changes subsequently come into effect.

These two features - the tug of divergent special interests and the fact that agreements must be reached before the environment to which they will apply is fully known-have always been of paramount concern to trade negotiators. They must be addressed in any useful model of negotiated liberalization.

At the close of any negotiations, the state of the world is revealed, governments implement tariff changes, and trade takes place. Once the period ends, factors become free to move between sectors, and, once they have done so, history repeats itself, with the initial tariffs for the new period equal to the final tariffs from the preceding period and with a new generation of policymakers, taking history as given, ready to consider further tariff changes.

\subsection{Government objectives}

Following Bagwell and Staiger (1999, 2001), I assume a government objective function sensitive both to domestic relative prices and to the terms of trade. But I further specify the functional form in several ways. For one, I suppose that domestic relative prices matter because they influence the distribution of income between factors specific to the export sector and those specific to the import sector, given the terms of trade, and I specify this distributional concern. Also, I allow the possibility that a government may be confronted with the need to decide upon a trade related policy: a policy that directly impacts its objective function but that also influences trade.

Specifically, I use the following objective function.

$\tilde{\phi}(s, a)=\left[\beta \frac{\Delta R_{x}(s, a)}{R_{x}}-\frac{1}{100}\left(-\frac{100 \Delta R_{m}(s, a)}{R_{m}}\right)^{1+\gamma}\right]+\tilde{\mu} \Delta M A(s, a)+\tilde{\lambda}(s, a)$,

where the three terms on the right reflect the implications, respectively, of distributional concerns, the terms of trade, and a possible trade-related policy action. $R_{x}$ and $R_{m}$ denote the real returns earned by factors specific to the export sector and to the importcompeting sector respectively. With trade liberalizations, $\Delta R_{x}>0, \Delta R_{m}<0$. The parameter $\beta$ denotes the weight the government attaches to $R_{x}$ relative to $R_{m}$ (presumably greater than unity if the export sector is larger than the import-competing sector, as it will be here). The parameter $\gamma>0$ captures the idea behind Corden's (1997, pp. 74-76) description of a conservative social welfare function: Governments avoid policies that would cause a serious reduction in the income of any interest group. ${ }^{4} \mathrm{I}$ accordingly refer to $\gamma$ as the Corden sensitivity. Here $\Delta M A=\left(\Delta X_{D}-\Delta M_{D}\right) / X$, the excess, at initial world prices, of the direct amount by which the tariff reduction would raise foreign demand for home exports over the direct amount it would raise home demand for imports (in terms of exportables), as a proportion of the initial trade

4 Hillman (1982) shows how Corden's concerns can be generated by a plausible political support function, and applications of Corden's ideas to trade policy are found in Deardorff (1987), Brander and Spencer (1994), and Ethier $(2002,2004)$. 
volume. This can be called the net exchange of market access. The parameter $\tilde{\mu}$, called the terms-of-trade sensitivity, reflects the impact $\triangle M A$ will produce on the terms of trade (the inverse of the familiar Marshall-Lerner term) multiplied by the importance the government attaches to this. The parameter $s$ indexes the (currently unknown) state of the world that will exist when the new tariff levels are in effect, and $a$ denotes a policy variable determined after $s$ is revealed (more on this later).

As Bagwell and Staiger $(1999,2001)$ aptly note, the first term on the right in my objective function, corresponding to internal distributional concerns, can be controlled unilaterally whereas manipulating the second term involves international spillovers: Our terms of trade is also our partner's terms of trade. Thus it is only the second consideration-a terms of trade externality - that can motivate trade agreements. I have two comments. First, the third term of my objective function also corresponds to an international externality, but the point of departure of this paper is that it is not possible to negotiate directly about it. Second, an earlier paper, Ethier (2004), used an objective function that incorporated the second term on the right above but that based it on political externalities between countries rather than on terms of trade externalities. Unlike the earlier paper, for the issues addressed in the two country model of this paper, it doesn't matter at all whether the negotiable externality between the two governments is political or terms-of-trade in origin: The reader is invited to take whichever interpretation he or she finds more congenial. ${ }^{5}$

\subsection{Unilateralism and reciprocity}

Ignore the trade-related action for the moment, and consider a unilateral reduction $\tau_{j}=(-\hat{t} /(1+t))$ in its tariff by a single country $i$. At unchanged world prices, the home relative price of imports falls by the amount of the tariff decrease, so that $\Delta R_{x}>0, \Delta R_{m}<0$, and $\Delta M A=-\varepsilon \tau_{i} M_{i}<0$, where $\varepsilon$ denotes the home price elasticity of import demand and $M_{i}$ the initial volume of imports. Define a liberalization as reciprocal if accompanied by foreign liberalizations that imply $\triangle M A=0$. Thus the second term of the governmental objective function vanishes. The following is immediate.

PROPOSITION 1. A government will never liberalize unilaterally, with a large enough Corden sensitivity $\gamma$ and terms of trade sensitivity $\tilde{\mu}$. However, it will always accept a sufficiently small reciprocal liberalization that implies $\beta \Delta R_{x} / R_{x}+$ $\Delta R_{m} / R_{m}>0$. It will never accept a move to free trade, provided that the Corden sensitivity $\gamma$ is sufficiently large.

Reciprocity neutralizes concern about market access, rendering the magnitude of $\tilde{\mu}$ irrelevant. In what follows I assume that the above conditions are fulfilled: Governments will not unilaterally liberalize, but they wish to negotiate reciprocal liberalizations that do not go all the way to free trade. It is easy to specify bargaining rules that imply equal gains and difficult to specify plausible rules that imply unequal gains: I assume

\footnotetext{
5 The political externality appears far more relevant to reality but the terms-of-trade externality is clearly more "politically correct" among trade theorists. So take your choice.
} 
all agreements feature reciprocal liberalization. I also assume that, because of preexisting countervailing-duty laws, trade cannot be subsidized: Tariffs are constrained to be nonnegative.

\subsection{The optimal reciprocal rate of liberalization}

Cconsider next the rate of reciprocal liberalization that both governments would, in the absence of trade related actions, regard as optimal: the optimal reciprocal rate of liberalization. To this end, rewrite the objective function as follows.

$$
\tilde{\phi}=\left[\beta \frac{\Delta R_{x}}{R_{x}}-\frac{1}{100}\left(-\frac{100 \Delta R_{m}}{R_{m}}\right)^{1+\gamma}\right]+\tilde{\mu} \Delta M A .
$$

Under present assumptions, a liberalization at the rate $\tau$ implies the following.

$$
\frac{\Delta R_{x}}{R_{x}}=\frac{\tau^{*}}{2} \quad \frac{\Delta R_{m}}{R_{m}}=-\frac{\tau}{2} \quad \Delta M A=\frac{\varepsilon X \tau^{*}-\varepsilon M \tau}{X}
$$

where $\tau^{*}$ denotes the partner country's liberalization. Substituting into the political support function and defining the transformation $\phi=2 \tilde{\phi} /(50)^{\gamma}, \mu=2 \tilde{\mu} /(50)^{\gamma}$ gives the following.

$$
\phi=\left[r^{\gamma} \tau^{*}-\tau^{1+\gamma}\right]+\mu \Delta M A
$$

where $r=(2 \beta)^{1 / \gamma} / 50$. The value of $\tau=\tau^{*}$ that maximizes $\phi$, the optimal reciprocal rate of liberalization, is therefore:

$$
\tau_{O R L}=r\left(\frac{1}{1+\gamma}\right)^{\frac{1}{\gamma}} .
$$

The optimal rate of liberalization can be interpreted as that rate which would be optimal for all governments were trade agreements complete contracts.

\section{A MODEL OF A DISPUTE SETTLEMENT PROCEDURE}

I now present a model of a DSP motivated by the earlier considerations. First, I must modify the sequence of events within each period to reflect the incomplete-contract nature of trade agreements and to include the operation of a DSP.

\subsection{Trade related actions}

Suppose that, ex post, some country may determine an action, $a$, which directly influences that government's level of political support and also affects that country's willingness to import. I am especially concerned with three types of uncertainty to which such an action would be subject ex ante. 1 Uncertainty (or complete ignorance) about what actual policy situation (environmental issues, health or safety concerns, etc., etc.) might give rise to such a potential action. 2 Uncertainty about the identity of the country in which the situation might emerge. 3 Uncertainty about the extent to which the potential action might be trade-related. To focus sharply on these concerns, I shall assume away all other sources of uncertainty. 
The first aspect is incorporated in the requirement that the trade agreement be an incomplete contract. Next, I suppose that exactly one issue will arise and that it will confer an opportunity for a trade related action on one country or the other, with an equal probability $(1 / 2)$ of either outcome.

In general, a trade-related action by some country may or may not be welcomed by its partners. But this paper concerns trade disputes. Consequently, I assume that such actions are always unwelcome: They cause the country undertaking the action to display more protection rather than less.

Specifically, I assume that implementing an action at the level $a(\geq 0)$ affects the country's demand for imports in the same way as would an increase in its tariff in the proportion $\alpha a$. Thus the trade-related action in effect reduces the country's liberalization from the negotiated rate $\tau$ to the rate $\tau-\alpha a$. The parameter $\alpha$ is a measure of how trade-related the action is: higher values of $\alpha$ correspond to more trade-relatedness. Furthermore, independently of its effect on the country's trade, the action has a net direct effect on the government's political support in the amount $\lambda(a)$. When a trade agreement is being negotiated, the value of $\alpha$ is not yet known but has an expected value of unity.

I assume, for simplicity, that the form of the function $\lambda$ is known at the time of negotiations. In particular, $\lambda(0)=0$ and $\lambda$ is strictly convex, increasing at a decreasing rate with $\lambda^{\prime \prime \prime} \geq 0$, reaching a maximum at $a=a_{O U A}$. Interpret $a_{O U A}$ as the optimal unilateral action: the action the government would take in the absence of trade consequences.

\subsection{The sequence of events}

The model features the following sequence of events.

1. Countries negotiate and then implement a reciprocal rate of liberalization $\tau$, and they also determine a DSP.

2. One country is then presented with the opportunity to make a trade related action $a$ not explicitly covered by the trade agreement, and this country (the potential defendant) determines $a$.

3. The trading partner (the potential complainant) then utilizes the DSP.

4. A fixed adjudication time is required for the DSP to reach a determination. During this time, the defendant continues with its action and no punishment is implemented.

5. The DSP renders a decision for the complainant, and the defendant must then decide whether to abide by the decision or to defy it. If it decides to abide, it sets $a=0$, and the sequence comes to an end.

6. If the defendant decides to violate the DSP decision, the complainant retaliates with trade restrictions proportional to the trade effects of the action $a$. The degree of proportionality is fixed by the trade agreement. The sequence now comes to an end.

\subsection{Possible outcomes}

The objective functions of the governments of the potential defendant $(D)$ and the potential complainant $(C)$ are as follows. 


$$
\begin{aligned}
& \phi^{D}=\left[r^{\gamma}(\tau-\alpha a)-(\tau-\alpha a)^{1+\gamma}\right]+\lambda(a)+\mu \varepsilon \alpha a \\
& \phi^{C}=\left[r^{\gamma} \tau-\tau^{1+\gamma}\right]-\mu \varepsilon \alpha a .
\end{aligned}
$$

Here, $\tau$ is negotiated before it is known which country will be $D$ and which will be $C$, and before the magnitude of $\alpha$ is known. After these are revealed, $D$ chooses $a$. These expressions are valid before the DSP decision is reached.

If $D$ complies with the DSP decision, $a$ becomes equal to zero in the above expressions. If $D$ refuses to comply and $C$ punishes, the expressions become:

$$
\begin{aligned}
\phi^{D} & =\left[r^{\gamma}(\tau-\alpha a)(\tau-\alpha a)^{1+\gamma}\right]-\mu \varepsilon(\rho-1) \alpha a+\lambda(a) \\
\phi^{C} & =\left[r^{\gamma}(\tau-\rho \alpha a)-(\tau-\rho \alpha a)^{1+\gamma}\right]+\mu \varepsilon(\rho-1) \alpha a
\end{aligned}
$$

where $\rho$ denotes the degree of proportionality for punishment allowed by the DSP.

For the period as a whole, the total value of each government's objective function is a weighted average of its value when the DSP is proceeding and its value after that procedure has run its course. Let $\delta(1 \geq \delta \geq 0)$ denote the weight given to the former and $1-\delta$ that given to the latter. $\delta$ is determined by the discount factor (which I assume exogenous and fixed) and by the amount of time allowed the DSP to do its business.

I can now describe the values of the objective functions of the two governments over the period as a whole. $\mathbf{i}$ If the DSP is not invoked or finds in favor of $D$ they are given by (3) above. ii If the DSP finds for $C$ and $D$ abides they are as follows.

$$
\begin{aligned}
\phi^{D}= & \delta\left\{\left[r^{\gamma}\left(\tau-\alpha a_{J}\right)-\left(\tau-\alpha a_{J}\right)^{1+\gamma}\right]+\mu \varepsilon \alpha a_{J}+\lambda\left(a_{J}\right)\right\} \\
& +(1-\delta)\left[r^{\gamma} \tau-(\tau)^{1+\gamma}\right] \\
\phi^{C}= & \delta\left\{\left[r^{\gamma} \tau-\tau^{1+\gamma}\right]-\mu \varepsilon \alpha a_{J}\right\}+(1-\delta)\left[r^{\gamma} \tau-(\tau)^{1+\gamma}\right] .
\end{aligned}
$$

Here $a_{J}$ denotes the action $D$ takes during the adjudication phase.

iii If the DSP finds for $C, D$ refuses to comply and continues to violate, and $C$ implements a punishment strategy, we have:

$$
\begin{aligned}
\phi^{D}= & \delta\left\{\left[r^{\gamma}\left(\tau-\alpha a_{J}\right)-\left(\tau-\alpha a_{J}\right)^{1+\gamma}\right]+\mu \varepsilon \alpha a_{J}+\lambda\left(a_{J}\right)\right\} \\
& +(1-\delta)\left\{\left[r^{\gamma}(\tau-\alpha a)-(\tau-\alpha a)^{1+\gamma}\right]-\mu \varepsilon(\rho-1) \alpha a+\lambda(a)\right\} \\
\phi^{C}= & \delta\left\{\left[r^{\gamma} \tau-\tau^{1+\gamma}\right]-\mu \varepsilon \alpha a_{J}\right\} \\
& +(1-\delta)\left\{\left[r^{\gamma}(\tau-\rho \alpha a)-(\tau-\rho \alpha a)^{1+\gamma}\right]+\mu \varepsilon(\rho-1) \alpha a\right\} .
\end{aligned}
$$

In light of one of the stylized facts ("The DSP of the WTO has almost always decided in favor of the complainant and, therefore, against the defendant"), I shall assume away case $\mathbf{i}$, that is, the DSP will always find for $C$. As argued earlier, use of the DSP implies that punishments will be delayed. Goals of the subsequent analysis include delineating when $D$ will abide by or violate the DSP ruling and explaining why punishments are tit-for-tat. 


\section{THE SUBSTANTIALLY EQUIVALENT WITHDRAWAL OF CONCESSIONS:}

A BASE CASE

The basic ideas of this paper are best illustrated by a special base case, which arises with two further assumptions, to be subsequently relaxed. $\mathbf{i}$ The DSP is fast enough so that governments give little weight to what happens before a decision is reached: $\delta=0$. ii The degree of trade-relatedness is known beforehand: $\alpha=1$.

Since $\delta=0$, this section can be interpreted as applying to situations in which the post-agreement decision of $D$ results not in a trade dispute but in an acceptable settlement with $C$ before the implementation of $a$. The parameter $\rho$ can be interpreted as stipulating in advance the principle (e.g., the equivalent withdrawal of concessions if $\rho=1$ ) to be applied to such settlements, and a purpose of this section is to endogenize the choice of $\rho$ more generally than just in a DSP. But as the balance of this paper will specifically deal with a DSP, I shall continue to employ the language of the latter.

If $D$ refuses to abide by a DSP ruling, or if a settlement is made, the government objective functions reduce to:

$$
\begin{aligned}
& \phi^{D}(a, \tau, \rho)=\left[r^{\gamma}(\tau-a)-(\tau-a)^{1+\gamma}\right]-\mu \varepsilon(\rho-1) a+\lambda(a) \\
& \phi^{C}(a, \tau, \rho)=\left[r^{\gamma}(\tau-\rho a)-(\tau-\rho a)^{1+\gamma}\right]+\mu \varepsilon(\rho-1) a .
\end{aligned}
$$

Consider first $D$ 's choice of $a$, given $\tau$ and $\rho$. This is determined by the first-order condition $\partial \phi^{D} / \partial a=0$, which reduces to

$$
\tau-a=\left[\frac{r^{\gamma}+\mu \varepsilon(\rho-1) \lambda^{\prime}}{1+\gamma}\right]^{\frac{1}{\gamma}}
$$

(I assume the second-order condition to be satisfied). If $\lambda^{\prime}$ does not exceed a critical positive value, this expression can be solved for $a(\tau, \rho)$ possessing the following properties.

$$
\tau>a \quad 1>\frac{\partial a}{\partial \tau}>0 \quad \frac{\partial a}{\partial \rho}<0 .
$$

Now turn to the negotiation stage. Assume each government wants to maximize the expected value of its objective function. Since each government has equal probability of turning out to be $D$ or $C$, both governments share a common ex ante objective equivalent to maximizing the sum $\phi^{D}+\phi^{C}$. The first order conditions are:

$$
\begin{aligned}
& \frac{d \phi^{D}}{d \tau}+\frac{d \phi c}{d \tau}=\phi_{\tau}^{D}+\phi_{a}^{D} \frac{\partial a}{\partial \tau}+\phi_{\tau}^{C}+\phi_{a}^{C} \frac{\partial a}{\partial \tau}=0 \\
& \frac{d \phi^{D}}{d \rho}+\frac{d \phi^{C}}{d \rho}=\phi_{p}^{D}+\phi_{a}^{D} \frac{\partial a}{\partial \rho}+\phi_{p}^{C}+\phi_{a}^{C} \frac{\partial a}{\partial \rho}=0 .
\end{aligned}
$$

Substituting, and setting $\phi_{a}^{D}=0$ because $D$ will subsequently choose $a$ optimally, 


$$
\begin{aligned}
& (1+\gamma)\left[(\tau-\rho a)^{\gamma}-(\tau-a)^{\gamma}\right] \\
& \quad+\left(2-\rho \frac{\partial a}{\partial \tau}\right)\left[r^{\gamma}-(1+\gamma)(\tau-a)^{\gamma}\right]+\frac{\partial a}{\partial \tau} \mu \varepsilon(\rho-1)=0 \\
& \frac{\partial a}{\partial \rho} \mu \varepsilon(\rho-1)-\left(a+\rho \frac{\partial a}{\partial \rho}\right)\left[r^{\gamma}-(1+\gamma)(\tau-\rho a)^{\gamma}\right]=0 .
\end{aligned}
$$

These are solved by $\rho=1$ and $\tau=a_{O U A}+\left[\frac{1}{1+\gamma}\right]^{\frac{1}{\gamma}} r$, for which the optimal subsequent choice of $a$ requires that $\gamma^{\prime}(a)=0$, that is, that $a=a_{O U A}$. Thus the solution of the negotiation phase plus $D$ 's choice of $a$ is given by the following.

$$
\tau=a_{O U A}+\left[\frac{1}{1+\gamma}\right]^{\frac{1}{\gamma}} r, \quad \rho=1, \quad a=a_{O U A} .
$$

So, commensurate punishment $(\rho=1)$ emerges endogenously. This can be regarded as a response to the reciprocal-conflict problem, as suggested above. But it does more than that. It ensures that the ultimate implications of $D$ 's actions on protection are reciprocal, which in turn allows the governments to negotiate an agreement that will allow the country that turns out to be $D$ to implement the optimal unilateral action and both governments to experience the optimal reciprocal liberalization.

Note, also, that this trade agreement ensures that $D$ will in fact take the action $a_{O U A}$ rather than no action at all: the latter would cause $D$ to experience more liberalization than desired in addition to forgoing the direct net benefit of acting. In other words, the two countries will reach a trade agreement that guarantees that the country that turns out to be $D$ will in fact defy a negative ruling by the DSP.

PROPOSITION 2 (substantially equivalent withdrawal of concessions). If no weight is given to the adjudication phase and if the degree of trade relatedness is known with certainty, the negotiated trade agreement will feature commensurate punishment, will induce D to violate the DSP, and will deliver, ex post, both the optimal degree of liberalization and the optimal unilateral action for $D$.

Consider in this light the hormone-fed beef case, widely regarded as a "failure" of the WTO system and as a threat to a "rules-based" international order for trade policy. An alternative interpretation might go as follows. "If governments thought that trade agreements would prevent them from responding to unforeseen deep political pressures of this sort (from the EU viewpoint), they would never sign on to those agreements in the first place. If they thought that such pressures would allow their trade partners to depart from reciprocity, they also would never sign on to such agreements in the first place. Under these circumstances, the experience of the hormone-fed beef case is probably the best feasible outcome, from the viewpoint of long term trade liberalization." Rosendorff (2000) offers a related analysis in which a DSP allows a country to "purchase" a release from its trade commitments, inducing it to agree to more liberalization than it would do in the absence of such a release. Perdikis, Kerr and Hobbs (2001) observe (p. 381), "It has always been recognized that for the WTO to be politically acceptable there have 
to be provisions which allow governments to ignore their WTO commitments when domestic pressure for protection becomes politically unmanageable." In other words, violation of DSP decisions can be thought of as an extra-legal counterpart, applying to a residual of unforeseen circumstances, to various GATT provisions (e.g., Articles XXII and XXIII) allowing the legal withdrawal of concessions.

Proposition 2 is, of course, consistent with this interpretation. But it also goes much further, suggesting the possibility of optimality properties of current arrangements.

Though the base case solution involves commensurate punishment, one can enquire how much added deterrence stronger punishments would provide. Define the elasticity of deterrence as

$$
\sigma \equiv-\frac{\rho}{a} \frac{\partial a}{\partial \rho}
$$

where $D$ chooses $a$ optimally, that is, to satisfy (7). Deterrence can be said to be strong, uniform, or weak according as $\sigma$ exceeds, equals, or falls short of unity. Strong deterrence means that a higher $e x$ ante punishment proportionality $\rho$ will result, at unchanged $\tau$, in less ex post punishment $\rho a$, and so forth.

At the base case solution, (7) implies that

$$
\sigma=-\frac{\mu \varepsilon / a_{\text {OUA }}}{\lambda^{\prime \prime}-\gamma r^{\gamma} / \tau_{\text {ORL }}}
$$

Thus deterrence elasticity is enhanced by a high terms of trade sensitivity $(\mu \varepsilon)$ or optimal rate of reciprocal liberalization $\left(\tau_{O R L}\right)$ and by a low willingness to protect $(\gamma)$, optimal unilateral action $\left(a_{O U A}\right)$, or low curvature $\left(-\lambda^{\prime \prime}\right)$ of the payoff from unilateral action.

\section{THE ADJUDICATION PHASE}

The base case gives strong results, but at the cost of suppressing essential aspects of the problem: the adjudication phase and the possibility of different degrees of trade relatedness $\alpha$. I now consider the implications of these features, proceeding one step at a time. I start by allowing a significant adjudication phase: $\delta>0$.

\subsection{The adjudication phase}

During the adjudication phase, $C$ cannot punish $D$, so the respective objective functions, during that period, are as follows.

$$
\begin{aligned}
& \phi_{J}^{D}=\left[r^{\gamma}\left(\tau-a_{J}\right)-\left(\tau-a_{J}\right)^{1+\gamma}\right]+\mu \varepsilon a_{J}+\lambda\left(a_{J}\right) \\
& \phi_{J}^{C}=\left[r^{\gamma} \tau-\tau^{1+\gamma}\right]-\mu \varepsilon a_{J} .
\end{aligned}
$$

During the adjudication phase, the optimal action $a_{j}(\tau)$ corresponding to each negotiated liberalization is implicitly defined by $D$ 's first order condition

$$
(1+\gamma)\left(\tau-a_{J}\right)^{\gamma}-r^{\gamma}+\mu \varepsilon+\lambda^{\prime}\left(a_{J}\right)=0 .
$$

This in turn implies that 


$$
1>\frac{d a_{J}}{d \tau}>0 \quad \frac{\partial a_{J}}{\partial \mu}>0 .
$$

Consider, initially, the trade agreement of the base case: $\tau=\tau_{O R L}+a_{O U A}$ and $\rho=1$. Then, with $\mu \varepsilon>0$, the first order condition requires that $a_{J}>a_{O U A}$. This reveals three influences of the adjudication phase on the objective functions of the two governments.

First, by taking the trade related action without punishment, $D$ 's objective function increases by $\mu \varepsilon a_{J}$ while $C$ 's falls a like amount. This departure from reciprocity might well induce ex post apoplectic outrage from $C$, but it has no direct ex ante effect since it does not change the joint welfare of the two governments. It has an indirect effect, however, because it induces $D$ to set $a_{J}$ higher than it otherwise would: $a_{J}>a_{\text {OUA }}$ implies that $\tau-a_{J}<\tau_{O R L}$ and $\lambda\left(a_{J}\right)<\lambda\left(a_{O U A}\right)$. Thus $D$ experiences less effective liberalization than it would otherwise like, and an excessive level of the action $a$, and this does reduce the joint welfare of the two governments. This is also true of the third effect: because $C$ cannot retaliate during the adjudication phase, it experiences "excessive" liberalization at the negotiated rate. (Another way of saying this is that the DSP causes the $C$ government to behave during the adjudication phase as though it had a lower willingness to protect $(\gamma)$ than it actually does-aggregate national welfare rises with the actual rate of liberalization).

\subsection{The trade agreement}

Next, take a step back to enquire whether setting $\delta>0$ would induce the two governments to reach a trade agreement different from that of the base case. The effect of a change in $\tau$ on the joint objective function during the adjudication phase, taking into account $D$ 's response in taking its optimal action $a_{J}(\tau)$, is as follows.

$$
\frac{d \phi_{J}^{D}}{d \tau}+\frac{d \phi_{J}^{C}}{d \tau}=\left[r^{\gamma}-(1+\gamma)\left(\tau-a_{J}\right)^{\gamma}\right]+\left[r^{\gamma}-(1+\gamma) \tau^{\gamma}\right]-\mu \varepsilon \frac{d a_{J}}{d \tau}
$$

With $\tau$ close to $\tau_{O R L}+a_{O U A}$, the first term on the right-hand side will be positive and the remaining two terms negative. For small values of $\mu \varepsilon, a_{J}$ will not be much greater than $a_{O U A}$, so that the first term on the right will be dominated by the second, and the entire expression is thus negative. An increase in $\mu \varepsilon$ will produce an increase in $a_{J}$, but it will magnify the third term more than the first (see the Appendix), so the entire expression will remain negative.

With the right-hand side negative, a small decrease in $\tau$ below $\tau_{O R L}+a_{O U A}$ will increase the joint welfare of the two governments during the adjudication phase. This will have no first-order effect on their joint welfare during the post-adjudication phase, where $\tau_{O R L}+a_{O U A}$ is first-best. Thus it generates a net overall benefit.

PROPOSITION 3. If the adjudication phase becomes of concern to the two governments (i.e., if $\delta$ becomes positive) they will negotiate a trade agreement with less liberalization than that of the base case.

Intuitively, if $\tau$ is reduced, $D$ will lower $a_{J}$. This affects $D$ in two ways: $a_{J}$ falls back toward $a_{O U A}$, increasing the non-trade benefits of the action; $a_{j}$ falls less than the reduction in $\tau$ itself so that $\tau-a_{j}$ falls, further worsening the deficient realized liberalization 
experienced by $D$. Thus, the reduction in the negotiated rate of liberalization induces $D$ to give more weight to the non-trade implications of the action, and less weight to the trade aspects, during the adjudication phase. Finally, the reduction in $\tau$ directly reduces the "excessive" liberalization experienced by $C$ during the adjudication phase, a clear benefit to the $C$ government at least.

Next turn to the implications of $\delta>0$ for the negotiated punishment factor $\rho$. The size of $\rho$ is irrelevant to the adjudication phase, but the fact that $\delta>0$ causes $\tau$ to deviate from its post-adjudication first-best value suggests that $\rho$ may also deviate from its post-adjudication first-best value (unity). The second equation in (8) above is the condition that $\rho$ be set optimally, from the ex ante point of view of each government. Using this expression to find the implicit derivative of $\rho$ with respect to $\tau$, assuming that $D$ sets $a$ optimally ex post, and evaluating the result at the base case trade agreement ( $\tau=\tau_{O R L}+a_{O U A}, \rho=1$ ) gives the following:

$$
a \frac{d \rho}{d \tau}=\frac{(\sigma-1)}{(\sigma-1)-\sigma \frac{\mu \varepsilon / a_{O U A}}{\gamma r^{\gamma} / \tau_{O R L}}} .
$$

Thus uniform deterrence ( $\sigma=1$ ) implies that $d \rho / d \tau=0$ : Commensurate punishment will still be negotiated. Weak deterrence $(\sigma<1)$ implies $1>\operatorname{ad} \rho / d \tau>0$. The reduction in $\tau$ reduces punishment, but in a dampened way: $a \rho$ falls by less than $\tau$. From (9), $\frac{\mu \varepsilon / a_{O U A}}{\gamma r^{\gamma} / \tau_{O R L}}>\sigma$. This in turn implies that strong deterrence gives $-1<a d \rho / d \tau<0$, punishment increases, but, again, in a dampened way.

The introduction of an adjudication phase results, during the post adjudication phase, in deficient ex post liberalization $\tau-a$ and in an excessive action $a$. Raising $\rho$ above unity worsens the former problem, since it causes $C$ to liberalize less ex post, but lessens the latter problem. Weak deterrence implies that the first effect will be predominant, so that $\rho$ should be reduced; strong deterrence implies the reverse.

The result, though, is an emphasis on commensurate punishment. This is preserved with uniform deterrence. Strong or weak deterrence produces deviations in the punishment factor $\rho$, but they are dampened in the sense that punishments $a \rho$ change less than $\tau$ itself.

The argument thus far in this section assumes that $D$ will violate the DSP ruling and that $C$ will punish. This is necessarily so in the base case, where the two countries will negotiate a trade agreement that guarantees violation. If the adjudication phase is not too important to the two governments relative to the post-adjudication phase (i.e., if $\delta$ is small enough), the trade agreement will be close enough to that of the base case still to guarantee violation. But large values of $\delta$ require that the possibility of $D$ abiding by the DSP ruling be considered. I turn to this next. To summarize results thus far,

PROPOSITION 4. For sufficiently small positive $\delta$, the two governments will negotiate a trade agreement in which $\tau<\tau_{O R L}+a_{O U A}$ and $\rho$ approximates unity. This will induce $D$ to violate the DSP ruling. 
Raising $\delta$ above zero causes $D$ to set $a_{J}>a_{O U A}>a$, and it also causes $C$ to experience "excessive" liberalization during the adjudication phase and deficient liberalization during the post-adjudication phase. The trade agreement induces $D$ to adjust its action closer to $a_{O U A}$ in each phase, enhancing the non-trade effects of the action, and it smooths out the variation of liberalization experienced by $C$.

\subsection{The pure adjudication case}

Consider now what the negotiated trade agreement would be if the negotiators gave no weight at all to the post-adjudication phase, that is, if $\delta=1$. This can be thought of as the polar opposite to the base case, where $\delta=0$. With $\delta=1$, the magnitude of the punishment coefficient $\rho$ is immaterial, so nothing is lost by setting it equal to unity.

The joint welfare of $C$ and $D$ equals

$$
W_{J}=\left[r^{\gamma}\left(\tau-a_{J}\right)-\left(\tau-a_{J}\right)^{1+\gamma}\right]+\left[r^{\gamma} \tau-\tau^{1+\gamma}\right]+\lambda\left(a_{J}\right) .
$$

The first-order ex ante optimality condition that $\tau$ be chosen to maximize $W_{J}$, taking into account that $D$ will subsequently choose $a_{J}$ optimally, reduces to

$$
\frac{d W_{J}}{d \tau}=(1+\gamma)\left\{\left[\tau_{O R L}^{\gamma}-\left(\tau-a_{J}\right)^{\gamma}\right]+\left[\tau_{O R L}^{\gamma}-\tau^{\gamma}\right]\right\}-\mu \varepsilon \frac{d a_{J}}{d \tau}=0 .
$$

If $\mu \varepsilon$ is sufficiently small, this condition implies that $\tau>\tau_{O R L}>\tau-a_{J}$. This in turn implies that $(1+\gamma)\left(\tau-a_{J}\right)^{\gamma}<r^{\gamma}$ which, for sufficiently small $\mu \varepsilon$, requires $\lambda^{\prime}\left(a_{J}\right)>0$, so that $a_{J}<a_{O U A}$. Conversely, if $\mu \varepsilon$ is sufficiently large, the first-order condition implies that $\tau_{O R L}>\tau>\tau-a_{J}$, whence $a_{J}>a_{O U A}$ for $\mu \varepsilon$ sufficiently large.

PROPOSITION 5. If terms of trade effects are sufficiently unimportant to the negotiators, a pure-adjudication-case trade agreement will result in D experiencing deficient liberalization and $C$ excessive liberalization and in $D$ choosing a level of the trade related action below the optimal unilateral level. Sufficiently important terms of trade effects result in both countries experiencing deficient liberalization and in D choosing a level of the trade related action above the optimal unilateral level.

\subsection{Abide or violate?}

Consider now the choice that $D$ must make at the end of the adjudication phase: whether to abide $(A)$ by the finding and set $a=0$ or to violate $(V)$ the finding and set $a$ equal to some positive value, knowing that this will induce punishment by $C$. The choice between the $A$ and $V$ strategies is independent of what $D$ did during the adjudication process, now past history.

Define $V(\tau, \rho)$ as follows.

$$
V(\tau, \rho)=\left[r^{\gamma}(\tau-a)-(\tau-a)^{1+\gamma}\right]+\mu \varepsilon(1-\rho) a+\lambda(a)-\left[r^{\gamma} \tau-\tau^{1+\gamma}\right]
$$

where

$$
(1+\gamma)(\tau-a)^{\gamma}-r^{\gamma}+\mu \varepsilon(1-\rho)+\lambda^{\prime}(a)=0 .
$$

$D$ will violate or abide by the ruling according as $V$ is positive or negative, and $V\left(\tau_{\text {ORL }}+a_{\text {OUA }}, 1\right)>0$. Define $W(\tau, \rho)$ as: 


$$
\begin{aligned}
W(\tau, \rho)= & \frac{1}{2}\left[r^{\gamma}(\tau-a)-(\tau-a)^{1+\gamma}\right]+\frac{1}{2}\left[r^{\gamma}(\tau-\rho a)-(\tau-\rho a)^{1+\gamma}\right] \\
& +\frac{1}{2} \lambda(a)\left[r^{\gamma} \tau-\tau^{1+\gamma}\right] .
\end{aligned}
$$

It will be optimal ex ante that whichever country turns out to be $D$ violate or abide by the ruling according as $W$ is positive or negative. Also, $W\left(\tau_{O R L}+a_{O U A}, 1\right)>0$ and $V(\tau, 1)=W(\tau, 1)+1 / 2 \lambda(a)$.

The above discussion of the pure adjudication case implied that, unless $\mu \varepsilon$ is small enough to prevent it, $\tau_{J}-a_{J}$ will be further enough from $\tau_{O R L}$ than will $\tau_{J}$ to ensure that

$$
\left[r^{\gamma}\left(\tau_{J}-a_{J}\right)-\left(\tau_{J}-a_{J}\right)^{1+\gamma}\right]<\left[r^{\gamma} \tau_{J}-\tau_{J}^{1+\gamma}\right] .
$$

This in turn implies that $V\left(\tau_{J}, 1\right)<0$ unless $\lambda\left(a_{J}\right)$ is large enough to prevent it. That is, unless trade related action is important enough to governments relative to trade concerns-as measured by $\mu \varepsilon$ - governments would prefer to abide by a negative determination, when the degree of liberalization is that of the pure adjudication case, rather than to violate it and experience the rollback of liberalization implied by violation cum commensurate punishment. I refer to this circumstance as the abidement property.

ABIDEMENT PROPERTY. $\mu \varepsilon$ is large enough relative to $\lambda\left(a_{J}\right)$ so that $V\left(\tau_{J}, 1\right)<$ 0 .

The definition of $V(\tau, \rho)$ implies that, when $\rho=1, V_{\tau}=(1+\gamma)\left[\tau^{\gamma}-(\tau-a)^{\gamma}\right]>0$ and $V_{p}=-\mu \varepsilon a<0$ so that

$$
\left.\frac{d \rho}{d \tau}\right|_{V=0, \rho=1}=\frac{(1+\gamma)\left[\tau^{\gamma}-(\tau-a)^{\gamma}\right]}{\mu \varepsilon a}>0 .
$$

Also, at $\rho=1, W_{\tau}=V_{\tau}+\lambda^{\prime} \frac{d a}{d \tau}$, which is positive with $\lambda^{\prime} \geq 0$, and $W_{p}=-\frac{a}{2}\left[r^{\gamma}-\right.$ $\left.(1+\gamma)(\tau-a)^{\gamma}\right]$, which is negative with $\lambda^{\prime}>0$. Accordingly,

$$
\left.\frac{d \rho}{d \tau}\right|_{W=0, \rho=1}=\frac{V_{\tau}+\lambda^{\prime} \frac{d a}{d \tau}}{\frac{a}{2}\left[\gamma^{\gamma}-(1+\gamma)(\tau-a)^{\gamma}\right]}>0 .
$$

Figure 1 depicts the plane of possible trade agreements $(\tau, \rho)$. The locus $V=0$ bisects the plane between those agreements that will induce the country that turns out to be $D$ to abide by or to violate the DSP ruling. The $W=0$ locus does the same on the basis of whether it is ex ante optimal that $D$ abide or violate. Point $\mathbf{B}$ denotes the base case agreement and must be in the violate zone. Point $\mathbf{J}$ denotes the pure adjudication agreement with $\rho=1$, and, if the abidement property holds, will be in the abide zone as depicted in the figure.

The ex ante optimal trade agreement is $\mathbf{B}$ if $\delta=0$ and $\mathbf{J}$ if $\delta=1$. Intermediate values of $\delta$ imply other agreements, possibilities illustrated by the bold line in Figure 1. Small values of $\delta$ yield agreements that will induce $D$ to violate the DSP ruling. As discussed above, these agreements will feature commensurate punishment if deterrence 


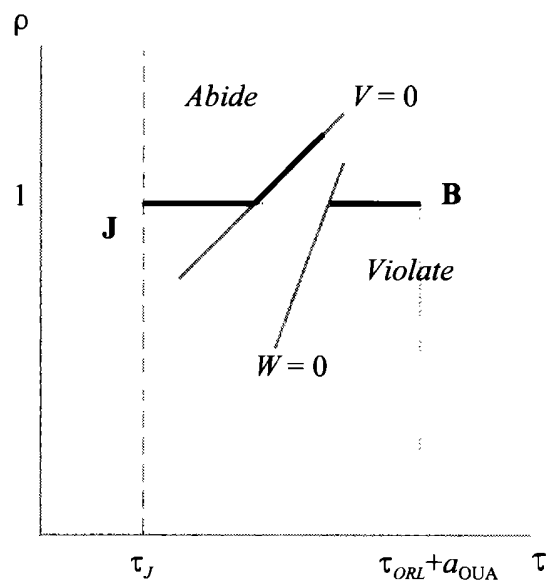

Figure 1. The Trade Agreement Plane.

is uniform, or dampened departures from commensurate punishment otherwise. If the abidement property holds, large values of $\delta$ yield agreements that will induce $D$ to abide by the ruling, and commensurate punishment suffices to ensure this.

Yet another possibility is for some range of intermediate values of $\delta$ to imply agreements between the $V=0$ and $W=0$ schedules. In such cases, an optimal agreement requires $D$ to abide by the DSP ruling, but commensurate punishment would induce $D$ to violate. See Figure 1. Thus punishment must be more severe than this, with $\rho$ at least large enough to correspond to points on the $V=0$ schedule.

The abidement property, however, tends to minimize the importance of such deviations from commensurate punishment. First, low values of $\lambda(a)$ reduce the distance between the two schedules when $\rho=1$, limiting the scope for such outcomes. Second, high values of $\mu \varepsilon$ flatten the $V=0$ schedule, limiting the required deviation above $\rho=1$.

PROPOSITION 6 (commensurate punishment). If the abidement property holds, there is a presumption that the optimal trade agreement will feature commensurate punishment, or approximately commensurate punishment.

With low values of $\delta$ the abidement property is irrelevant for commensurate punishment, or a dampened departure from it, as we saw above. High values of $\delta$ render the property important. Commensurate punishment is one of the two key results of this section. The second is the delineation of the circumstances under which $D$ will abide by or violate the DSP ruling.

PROPOSITION 7 (abide or violate). If the abidement property holds, the optimal trade agreement will induce $D$ to abide by the DSP ruling when the negotiators attach more importance to the adjudication phase (large $\delta$ ), and to violate it when they attach less importance (low $\delta$ ). 
Why low values of $\delta$ induce violation is clear from the earlier discussion of the base case. When $\delta$ is large, so the adjudication phase is important, the negotiators, knowing that they have no way of preventing $D$ from implementing $a$ during that phase, will negotiate less liberalization to reduce the incentive for $D$ to set a large $a$. But when the post adjudication phase commences, this lower negotiated liberalization will increase the damage of further backsliding with violation cum commensurate punishment. Thus the agreement should induce $D$ to abide.

Thus abiding by the DSP during the post adjudication phase is associated with more (not less) emphasis on the adjudication phase, during which $D$ is free to violate without punishment. This should not be interpreted to mean that high values of $\delta$ are desirable because they limit international conflict. Indeed, since the base case is first-best, there is a presumption that the negotiators would prefer lower values of $\delta$ and therefore would try to design the adjudication process so that $\delta$ is as small as is consistent with the integrity and credibility of that process. Attempting to do just this was a main objective of the revision of the GATT DSP undertaken during the Uruguay Round.

\section{THE DEGREE OF TRADE RELATEDNESS}

Thus far I have assumed that the negotiators know beforehand what the degree of trade relatedness will be, that is, that $\alpha$ assumes its expected value (unity) with certainty. Now this will be relaxed. It will be convenient to assume that the negotiators are risk neutral with respect to such uncertainty, and proceed on the basis of the expected value of $\alpha$, reaching the agreement described above. The first problem, then, is to determine how, given this agreement, ex post behavior will depend upon the realization of $\alpha$.

The timing is as follows. First, the governments negotiate a trade agreement $(\tau, \rho)$. Next, the identity of $D$ and the magnitude of $\alpha$ are revealed. Then, as above, $D$ chooses $a_{J}$, the DSP rules against $D$, and $D$ decides whether to abide by or to violate the ruling. The interesting question is how this decision is influenced by the realization of the degree of trade relatedness.

\subsection{Abide or violate redux}

When $\alpha$ can deviate from unity, the terms critical for the decision whether to abide or to violate, and for whether either decision is desirable, become

$$
\begin{aligned}
V(\tau, \rho)= & {\left[r^{\gamma}(\tau-\alpha a)-(\tau-\alpha a)^{1+\gamma}\right] } \\
& +\mu \varepsilon(1-\rho) \alpha a+\lambda(a)-\left[r^{\gamma} \tau-\tau^{1+\gamma}\right]
\end{aligned}
$$

where

$$
\alpha(1+\gamma)(\tau-\alpha a)^{\gamma}-\alpha r^{\gamma}+\mu \varepsilon \alpha(1-\rho)+\lambda^{\prime}(a)=0,
$$

and

$$
\begin{aligned}
W(\tau, \rho)= & \frac{1}{2}\left[r^{\gamma}(\tau-\alpha a)-(\tau-\alpha a)^{1+\gamma}\right]+\frac{1}{2}\left[r^{\gamma}(\tau-\rho \alpha a)^{1+\gamma}\right. \\
& +\frac{1}{2} \lambda(a)-\left[r^{\gamma} \tau-\tau^{1+\gamma}\right]
\end{aligned}
$$


These expressions imply, if $\rho=1$ and $\alpha=1$ initially,

and

$$
\frac{d V}{d \alpha}=-a \lambda^{\prime}(a)<0
$$

$$
\frac{\partial a}{\partial \alpha}=\frac{\lambda^{\prime}+\gamma(1+\gamma) a(\tau-a)^{\gamma-1}}{\lambda^{\prime \prime}-\gamma(1+\gamma)(\tau-a)^{\gamma-1}}<0
$$

and

$$
\frac{d W}{d \alpha}=a\left[(1+\gamma)(\tau-a)-r^{\gamma}\right]+\frac{1}{2} \lambda^{\prime}(a) \frac{\partial a}{\partial a}<0 .
$$

When $\rho=1, V_{\tau}>0$ and $W_{\tau}>0$, as shown above. Thus:

$$
\left.\frac{d \tau}{d \alpha}\right|_{V=0, \rho=1}>0,\left.\quad \frac{d \tau}{d \alpha}\right|_{W=0, \rho=1}>0 .
$$

An increase in $\alpha$ above unity will shift the $V=0$ and $W=0$ schedules to the right, causing some trade agreements that would have caused $D$ to violate the DSP ruling (with $\alpha=1$ ) to instead cause $D$ to abide by the ruling. A reduction of $\alpha$ below unity does the reverse.

PROPOSITION 8. A realization of high trade relatedness $(\alpha>1)$ increases the set of trade agreements inducing the country that turns out to be D to abide by the DSP ruling. A realization of low trade relatedness $(\alpha<1)$ reduces the size of that set.

When $D$ decides whether to abide or violate, it weighs the favorable direct effect of violation against the unfavorable reduction in liberalization implied by violation cum punishment. A high degree of trade relatedness enhances the second, negative, consideration. This can be enough to transform a decision to violate into one to abide for agreements close to $V=0$, where the two effects balance out.

\subsection{Commensurate punishment redux}

Negotiators, aware of the possible effects consequent upon the ex post realization of $\alpha$, might possibly negotiate a different punishment proportion $\rho$ as a result. Suppose, for example, that the negotiators settle on an agreement to the left of the $V=0$ schedule, which will therefore induce $D$ to abide by the DSP ruling if $\alpha$ attains its expected value of unity. Consider the effect of altering this agreement by raising $\rho$ above unity.

This alteration will be of no consequence whenever the degree of trade relatedness is equal to or above its expected value, because $D$ will still abide. If the degree of trade relatedness turns out below its expected value it could cause the agreement, with $\rho=1$, to lie between the $V=0$ and $W=0$ schedules, so that $D$ would choose to violate the DSP ruling even though that would lower the joint welfare of the two governments. If, instead, $\rho$ had been set above unity by enough, that could induce $D$ to abide by the ruling, a social benefit. Even if $D$ still violates, the higher $\rho$ would induce a lower $a$. A final possibility is that the realized degree of trade relatedness is enough below average so that the trade agreement, with its higher value of $\rho$, ends up below the $W=0$ schedule. In this case, having raised $\rho$ above unity causes it to be even further from 
its optimal ex post value if deterrence is uniform or weak, and this must lower joint welfare. With strong deterrence, the increase in $\rho$ might have moved it either towards or away from its optimal value.

Now suppose instead that the negotiators settle on an agreement to the right of the $W=0$ schedule, which will therefore induce $D$ to violate the DSP ruling if $\alpha$ attains its expected value of unity. In this case, altering the agreement by raising $\rho$ above the level that is optimal when $\alpha=1$ must lower joint welfare ex post whenever the realized degree of trade relatedness is equal to or below its expected value. If $\alpha$ ends up above unity by enough to leave the agreement between the $V=0$ and $W=0$ schedules an increase in the negotiated $\rho$ could either raise or lower ex post joint welfare, and it would have no effect should the realized degree of trade relatedness be sufficient to put the agreement to the left of $V=0$.

Note that the abidement property tends to work against the possibility that uncertainty about $\alpha$ could induce the negotiators to increase $\rho$ when the optimal ex ante agreement lies above the $V=0$ schedule. By reducing the difference between the $V=0$ and $W=0$ schedules it lowers, other things equal, the chances that the realization of $\alpha$ will leave the trade agreement between those two schedules. By flattening the $V=0$ schedule it lowers the amount by which increasing $\rho$ could conceivably be beneficial.

All in all, it seems quite unlikely that uncertainty about the degree of trade relatedness would induce negotiators to increase $\rho$ significantly. But it is possible to construct examples where this would happen-for example, a magnitude of $\delta$ implying (when $\alpha=1$ ) a trade agreement somewhat to the left of the $V=0$ schedule combined with a subjective probability distribution over $\alpha$ giving no likelihood to the realization of low enough degrees of trade relatedness to leave the negotiated agreement to the right of the $W=0$ schedule.

\section{CONCLUDING REMARKS}

This paper explores the idea that observed dispute settlement procedures and punishments are responses to the fact that trade agreements are necessarily incomplete contracts. I argue that this perspective can explain prominent features of these procedures and punishments and also has implications for the trade agreements themselves. The argument can be summarized as follows.

- Trade agreements are of necessity incomplete contracts because trade can be affected by all sorts of potential policies that countries can either not foresee or not be willing to negotiate about.

- If no weight is given to the adjudication phase and if the degree of trade relatedness is known with certainty, the negotiated trade agreement will induce the defendant to violate the DSP and will deliver, ex post, both the optimal degree of liberalization and the optimal unilateral action for the defendant.

- This suggests a central role, in the process of multilateral trade liberalization, for an implicit agreement to allow countries to violate agreed commitments if the violation implies no retreat from reciprocity. It also provides an argument for the 
principle of the equivalent withdrawal of concessions, which has permeated the GATT from its very begining.

- If the adjudication phase of a DSP is of concern to the two governments they will negotiate a trade agreement with less liberalization.

- The abidement property - that trade matters sufficiently to governments relative to trade related action-implies a presumption that the optimal trade agreement will feature commensurate punishment, or approximately commensurate punishment. That is, the principle of the equivalent withdrawal of concessions, or something close to it, should apply to dispute settlement also.

- If the abidement property holds, the optimal trade agreement will induce the defendant to abide by the DSP ruling when the negotiators attach more importance to the adjudication phase, and to violate it when they attach less importance.

- A realization of high trade relatedness increases the set of trade agreements inducing the country that turns out to be $D$ to abide by the DSP ruling. A realization of low trade relatedness reduces the size of that set.

The principle of the equivalent withdrawal of concessions - or of commensurate punishment-has a vital implication for negotiated trade liberalization. A trade agreement can, in the end, deliver liberalization no greater than that desired, ex post, by the more reluctant liberalizer. ${ }^{6}$

A question for future research suggested by the above is: What are the implications of uncertainty about the direct magnitude on governments' objective functions of the trade related actions? The important role of the abidement property (essentially that the trade consequences of such actions be sufficiently important relative to the direct consequences) suggests that this is an important question.

This paper also raises another question for future research. With the WTO, essential stylized facts of the DSP are enshrined in trade agreements. Before that they were still present but apparently as elements of an "implicit" contract. Does such "implicitness" matter? Or, put another way, does it matter that such stylized facts are now enshrined in the WTO?

\section{REFERENCES}

Bagwell, K. and R. W. Staiger (1999), “An Economic Theory of GATT,” American Economic Review 89 (1), March, 215-248.

Bagwell, K. and R. W. Staiger (2001), "Domestic Policies, National Sovereignty, and International Economic Institutions," Quarterly Journal of Economics 116 (2), May, 519-562.

Brainard, S. L. and T. Verdier (1994), "Lobbying and Adjustment in Declining Industries," European Economic Review 38, 586-595.

Brander, J. and B. Spencer ( 1994), “Trade Adjustment Assistance: Welfare and Incentive Effects of Payments to Displaced Workers," Journal of International Economics, 239-261.

Bütler, M. and H. Hauser (2000), "The WTO Dispute Settlement System: A First Assessment from An Economic Perspective," The Journal of Law, Economics, and Organization 16 (2), 503-533.

Corden, W. M. (1997). Trade Policy and Economic Welfare, $2^{\text {nd }}$ ed. (Oxford: Oxford University Press).

6 I have exploited this implication in Ethier (2002). 
Deardorff, A. (1987), "Safeguards Policy and the Conservative Social Welfare Function." In: Kierzkowski, H. K. [ed.], Protection and Competition in International Trade (Oxford: Blackwell).

Ethier, W. J. (2004), "Political Externalities, Nondiscrimination, and A Multilateral World," Review of International Economics 12 (3), pp 303-320.

Ethier, W. J. (2002), "Unilateralism in A Multilateral World," The Economic Journal 112 (479), 266-292.

Furusawa, T. (1999), "The Role of the WTO Dispute Settlement Procedure on International Cooperation," unpublished manuscript.

Hillman, A. L. (1982), "Declining Industries and Political-Support Protectionist Motives," American Economic Review 72, 1180-1190.

Hungerford, T. L. (1991), “GATT: A Cooperative Equilibrium in A Noncooperative Trading Regime?" Journal of International Economics 31, 357-369.

Kovenock, D. and M. Thursby (1992), "GATT, Dispute Settlement and Cooperation," Economics \& Politics 4, $151-170$.

Long, N. V. and N. Vousden (1991), "Protectionist Responses and Declining Industries," Journal of International Economics 30, 87-103.

Ludema, R. (2001), "Optimal International Trade Agreements and Dispute Settlement Procedures," European Journal of Political Economy 17 (2), 355-376.

Maggi, G. (1999), "The Role of Multilateral Institutions in International Trade Cooperation," American Economic Review 89 (1), 190-214.

Ohyama, M. (1972), “Trade and Welfare in General Equilibrium," Keio Economic Studies IX (2), 37-73.

Perdikis, N., W. A. Kerr, and J. E. Hobbs (2001), "Reforming the WTO to Defuse Potential Trade Conflicts in Genetically Modified Goods," The World Economy 24 (3), 379-398.

Rosendorff, B. P. (2000), "Stability and Rigidity: The Dispute Settlement Procedure of the WTO," unpublished manuscript, School of International Relations, University of Southern California.

Staiger, R. (1995), "International Rules and Institutions for Cooperative Trade Policy." Chapter 29 in Grossman, G. M. and K. Rogoff [eds.], Handbook of International Economics, Volume 3 (Amsterdam: Elsevier), 1495-1551.

\section{APPENDIX: IMPLICATIONS OF THE AdJUdiCATION PHASE FOR THE TRADE AGREEMENT}

\section{The rate of liberalization}

The condition (11) that $a_{j}$ be optimally chosen implies that

$$
1>\frac{\partial a_{J}}{\partial \tau}>0 \text { and } \frac{\partial a_{J}}{\partial \tau}=\gamma(1+\gamma)\left(\tau-a_{J}\right)^{\gamma-1} \frac{\partial a_{J}}{\partial(\mu \varepsilon)}>0 .
$$

Now for small values of $\mu \varepsilon$, the right-hand side of (12) is necessarily negative. The response of this right-hand side to a change in $\mu \varepsilon$, in light of (17), is just

$$
\begin{aligned}
-\mu \varepsilon \frac{\partial^{2} a_{J}}{\partial \tau \partial(\mu \varepsilon)}= & -\left(\frac{\partial a_{J}}{\partial(\mu \varepsilon)}\right)^{2} \\
& \times\left\{-\gamma(1-\gamma)(1+\gamma)\left(\tau-a_{J}\right)^{\gamma-2}\left[1-\frac{\partial a_{J}}{\partial \tau}\right]-\lambda^{\prime \prime \prime} \frac{\partial a_{J}}{\partial \tau}\right\}>0 .
\end{aligned}
$$

Thus the right-hand side of (12) is necessarily negative for all values of $\mu \varepsilon$. 